\title{
Restricted Migration of Transplanted Oligodendrocytes or their Progenitors, Revealed by Transgenic Marker M $\beta$ P
}

\author{
Victor L. Friedrich, Jr. and Robert A. Lazzarini \\ Brookdale Center for Molecular Biology and Fishberg Research Center for Neurobiology \\ Mount Sinai School of Medicine, New York, NY, USA
}

\begin{abstract}
Transgenic mice of line $\mathrm{M} \beta \mathrm{P3}$ express bacterial $\beta$-galactosidase in oligodendrocytes but not other cells of the CNS. The marker enzyme, demonstrated histochemically or by immunostaining in oligodendrocyte cell bodies and along myelin internodes, appears at the time of myelination and persists thereafter; in transplantation experiments, the marker may serve to indicate both the source of particular cells and their state of differentiation. The subventricular zone of the lateral ventricle, grafted from transgenic to wild-type perinatal recipient mice, yields histochemically labeled oligodendrocytes in surrounding host tissue. When grafts are placed in cerebral cortex near callosal radiations, graft-derived oligodendrocytes are found in cerebral cortex and subcortical white matter as far as $1.5 \mathrm{~mm}$ from the site of implant but not in nearby caudoputamen. This study is the first to document differentiation of transplant-derived oligodendrocytes in normal developing CNS. Our results are consistent with the wellestablished notion that oligodendrocyte progenitors migrate during normal development and suggest that such migration might be guided or restricted by mechanisms yet to be identified.
\end{abstract}

\footnotetext{
Reprint address:

V. L. Friedrich, Jr.

Brookdale Center for Molecular Biology, Box 1126

Mount Sinai Medical Center

One Gustave L. Levy Place

New York, NY 10029-6574, USA
}

\section{KEY WORDS}

myelin, oligodendrocyte, development, gliogenesis, $\mathrm{O} 2 \mathrm{~A}, \boldsymbol{\beta}$-galactosidase

\section{INTRODUCTION}

The behavior of transplanted oligodendrocytes and oligodendrocyte progenitors in normal host tissue has largely been obscured by a lack of effective markers. Previous studies have demonstrated migration of transplanted oligodendrocytes or their progenitors into host CNS experimentally depleted of oligodendrocytes or genetically dysmyelinated $15 /$; however, the behavior of oligodendrocytes and their progenitors transplanted into normal developing CNS remains largely unexplored.

$\mathrm{M} \beta \mathrm{P}$, recently constructed in our laboratory, is a chimeric gene containing the E.coli lacZ ( $\beta$ galactosidase) coding sequence flanked by segments of the murine myelin basic protein (MBP) and myelin proteolipid protein genes. This construct is expressed strongly and specifically in oligodendrocytes, whose cell bodies and processes are readily visualized in transgenic mice by $\mathrm{X}$-gal histochemical staining and by immunofluorescence for the transgene protein $/ 2 /$. Transgene expression is negligible at birth and increases dramatically as myelination progresses; it parallels that of the endogenous MBP gene, both in vivo and in dispersed cell culture.

The transgenic mice show normal CNS architecture and are well myelinated. Since the transgene has no evident effect on development or function of the CNS, it is a suitable marker for transplantation studies. In the studies described 
here, we transplanted tissue pieces from brains of M $\beta P$ transgenic mice into those of perinatal wild type hosts and obtained labeled, differentiated oligodendrocytes in host structures. In this first view of the behavior of oligodendrocyte/progenitor cells transplanted into normal CNS, we find clear evidence that cells of this lineage migrate out of transplants, and that such migration is guided or restricted by host structures.

\section{MATERIALS AND METHODS}

\section{The M $\beta P$ transgene and line M $\beta P 3$}

The M $\beta P$ transgene, described in detail elsewhere $/ 2 /$, consists of the lacZ gene of E.coli flanked upstream r a $1.9 \mathrm{~kb}$ fragment of the promoter-enhancer region of the murine MBP gene and downstream by a fragment of the human myelin proteolipid (PLP) gene. Line MBP3 is one of several generated with this construct; it was chosen for the present study because the line shows strong expression of the transgene, limited to oligodendrocytes $/ 2 /$. Donor mice were obtained from matings of heterozygous transgenics $(\mathrm{Tg} /-)$ of a mixed C57B1/6J x DBA/2J background with wild type (-/-) mice which were the $F 1$ progeny of those two inbred strains. The donor litters were mixed $\mathrm{Tg} /$ - and wild type; the genotype of each donor was determined by X-gal staining of spinal cord pieces, as described below.

\section{Transplantation}

Donor mouse pups, from 1 to 3 days after birth, were sacrificed by decapitation. Brains were removed and slices of brain were laid flat in sterile Petri dishes. Each slice was penetrated at the dorsolateral margin of the lateral ventricle by a $5 \mu \mathrm{l}$ Hamilton syringe equipped with a blunt-ended 25 ga needle mounted on a stereotaxic device, and a volume of $0.1-0.2 \mu \mathrm{l}$ of tissue was drawn into the needle. Recipient mice of similar age were anesthetized by hypothermia and placed in the stereotaxic device. Following craniotomy, the loaded syringe needle was lowered into the cerebral cortex, and the plug of tissue it contained was ejected approximately $0.5-1 \mathrm{~mm}$ caudal to bregma,
$1 \mathrm{~mm}$ from the midline, and $1 \mathrm{~mm}$ from the cortical surface. Following withdrawal of the needle, the wound was closed and the pups were returned to their mothers.

\section{Histochemistry}

At least 30 days post-transplantation, recipients were anesthetized and fixed by vascular perfusion with buffered formaldehyde. Brains were removed and coronal sections were cut serially at $50 \mu \mathrm{m}$ thickness on a Vibratome. Sections were stained for bacterial $\beta$-galactosidase by incubation in a solution containing $0.15 \mathrm{M} \mathrm{NaCl}, 10 \mathrm{mM}$ $\mathrm{Na}_{2} \mathrm{HPO}_{4}, 35 \mathrm{mM} \mathrm{K}_{3} \mathrm{Fe}(\mathrm{CN})_{6}, 35 \mathrm{mM} \mathrm{K}_{4} \mathrm{Fe}(\mathrm{CN})_{6}$, $2 \mathrm{mM} \mathrm{MgCl}, 0.01 \%$ sodium deoxycholate, $0.02 \%$ Nonidet NP-40 (Sigma) and 0.05\% X-gal (5bromo-4-chloro-3-indolyl- $\beta$-galactoside; GIBCO$\mathrm{BRL}$ ), final $\mathrm{pH}$ 7.0. Sections were examined without counterstaining using brightfield, phase and Nomarski optics; illustrations for this paper were obtained with brightfield optics.

\section{RESULTS}

\section{Histochemical characterization of transgenically labeled oligodendrocytes}

The M $\beta P 3$ transgene drives expression of a bacterial $\beta$-galactosidase coding sequence in oligodendrocytes but not in other cells of the CNS /2/. Reaction conditions specific for the bacterial enzyme yielded strong histochemical staining of white matter in transgenic mice (Fig. 1A), with no staining of wild type (nontransgenic) controls (Fig. 1B). Stained cell bodies were clearly visible in the transgenic white matter, surrounded by diffusely distributed reaction product, and also occurred in those gray matter regions containing myelinated axons (Fig. 2).

Oligodendrocytes emit numerous processes joining cell bodies with their myelin sheaths, and Golgi-impregnated oligodendrocytes were readily identified by their characteristic shapes $/ 6 /$. These processes were also visible in X-gal stained sections from the transgenic mice (Fig. 3), indicating that the marker enzyme was present, within processes, at a distance from the cell body. 


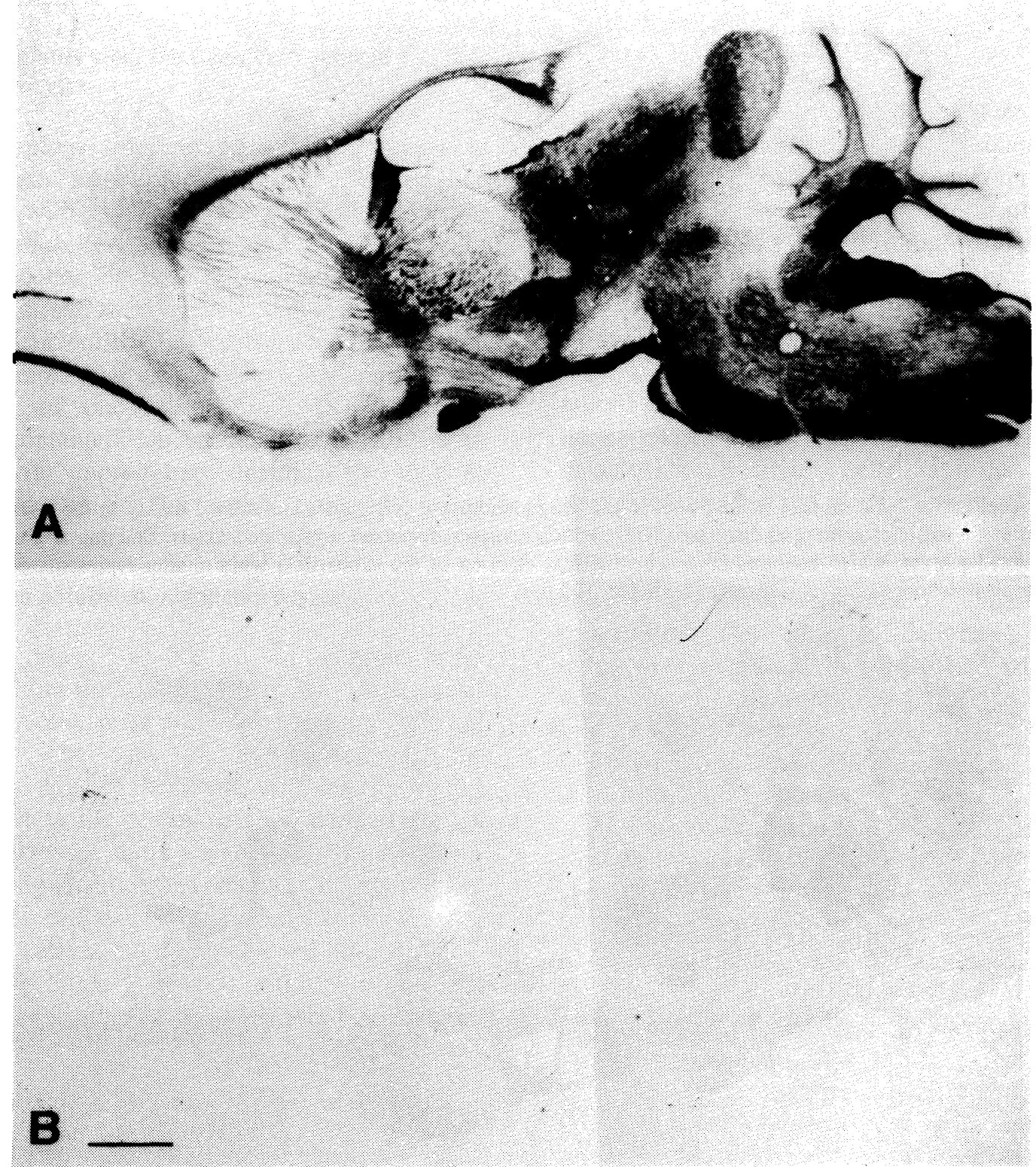

Fig. 1: Sagittal sections from the brains of an M $\mathrm{PP} 3$ transgenic mouse (A) and a control (wild type) mouse (B), stained with Xgal for bacterial $\beta$-galactosidase. The transgenic mouse shows strong staining of white matter throughout the brain, while the control mouse shows no staining. Scale bar, $1 \mathrm{~mm}$. 


\section{ML}

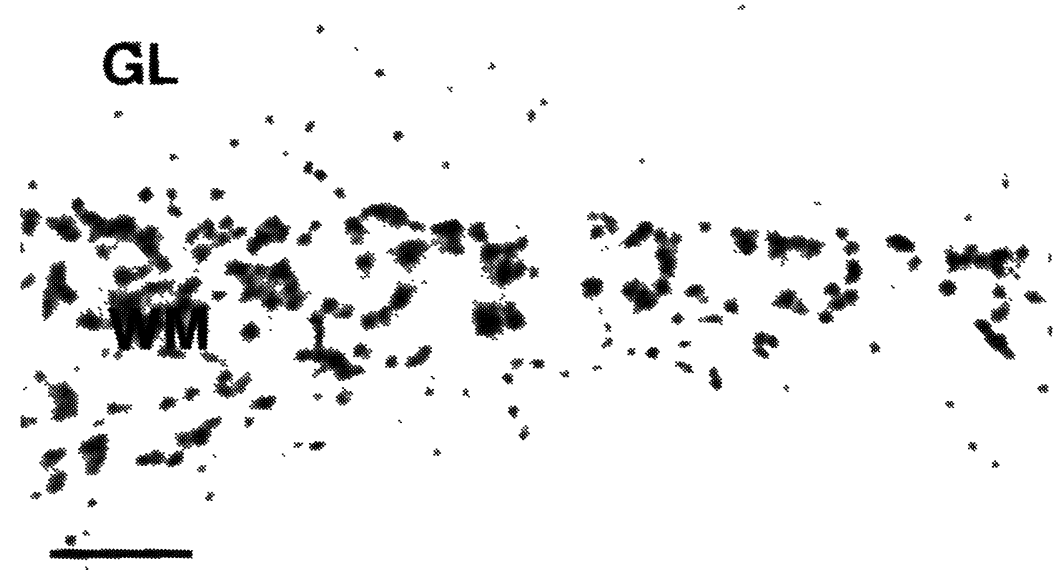

Fig. 2: Cerebellum of M $\beta P$ mouse, stained with X-gal. Oligodendrocyte cell bodies are stained darkly in the subcortical white matter (WM) and in the granular layer (GL), which contains dispersed myelinated axons. Staining is absent from the molecular layer, which contains no myelin. Diffuse staining of the subcortical white matter represents enzyme in the cytoplasmic loops of myelin sheaths. Scale bar, $100 \mu \mathrm{m}$.

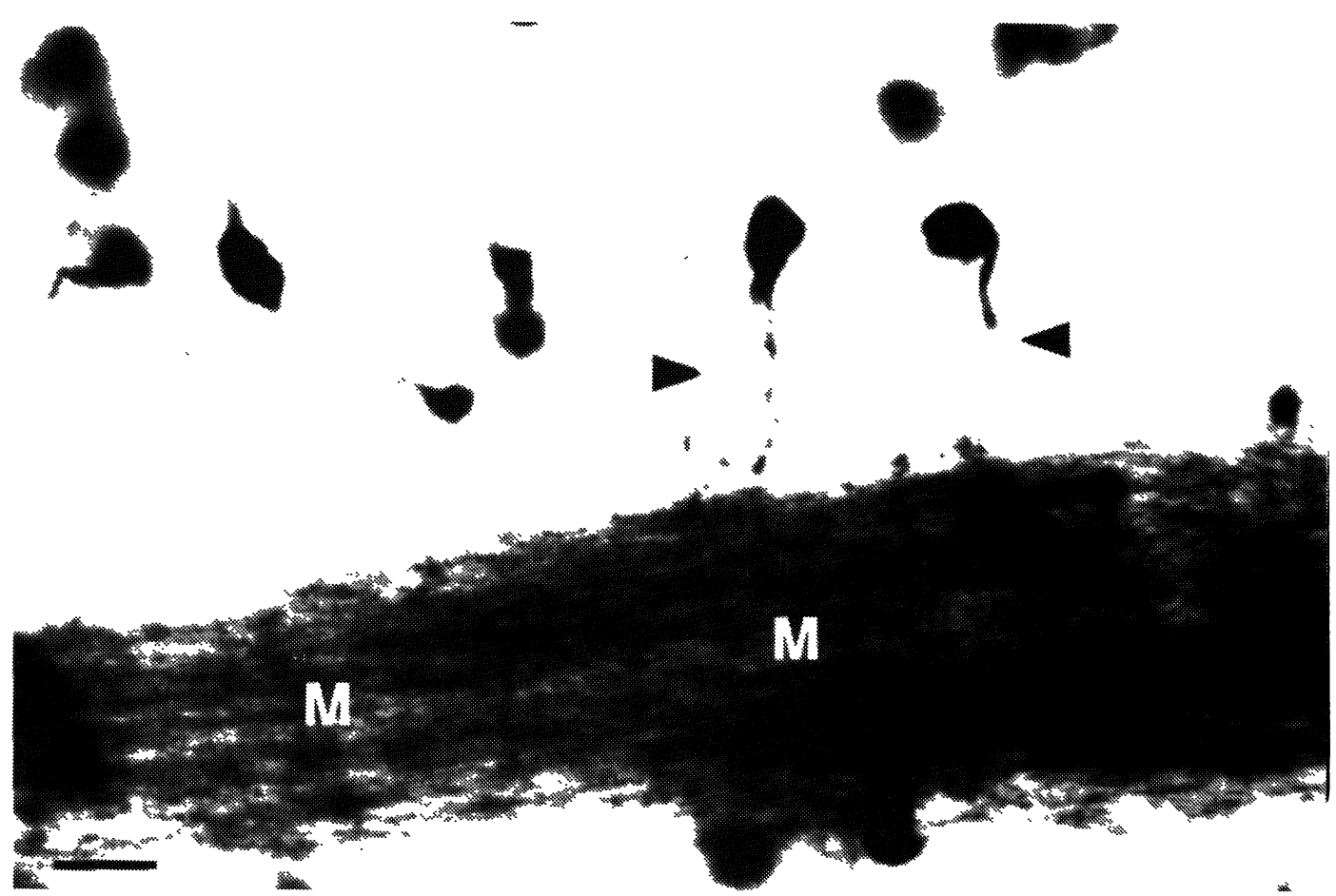

Fig. 3: Caudoputamen of an M $\beta P$ transgenic mouse, stained with X-gal. Oligodendrocyte cell bodies are clearly visualized. Characteristic stained processes (arrowheads) join the cell bodies with nearby stained myelinated bundles(M). Scale bar, $20 \mu \mathrm{m}$. 
Individual X-gal stained myelinated axons could often be followed in gray matter, indicating that the enzyme was also present in the cytoplasmic loops of myelin sheaths.

\section{CNS transplants yield transgenically labeled oligodendrocytes}

Tissue plugs from perinatal M $\beta \mathrm{P} 3$ transgenic mouse brain were placed into the cerebra of perinatal wild type hosts. At the time of transplantation, few oligodendrocytes were present in either donor or host brains. Recipients were sacrificed at age four weeks or beyond, a survival interval sufficient to allow substantial myelination of host mouse brain (e.g. /4,7/) and robust expression of the transgene $/ 2 /$. X-gal stained sections contained labeled cells, isolated or in groups, with morphology identical to that of oligodendrocytes in the native transgenic mice (Fig. 4).

\section{Distribution of labeled oligodendrocytes}

Tissue plugs $0.1-0.2 \mu \mathrm{l}$ in volume were extracted from the subventricular zone of perinatal transgenic donor mice and implanted into perinatal recipients. The site of extraction was the dorsolateral edge of the lateral ventricle; the site of implant was in the nearby cerebral cortex (Fig. 5). After 30 days or more survival, we found graftderived oligodendrocytes mainly in subcortical white matter and callosal radiations, with a smaller number of cells in overlying cerebral cortex. A few cells were located in the fornix and ventral hippocampal commissure, near their contact with the corpus callosum. We found no evidence of long distance migrations like those obtained when host mice are dysmyelinated $/ 5 /$, but the design of our experiments may not have favored such migrations.

We did not see labeled cells in the caudoputamen, even that immediately subjacent to labeled subcortical white matter. Since geometry appears to favor passage of cells into the caudoputamen, we wondered if the caudoputamen might present an environment hostile to the differentiation of the engrafted cells. Deeper implants excluded that possibility: numerous $\beta$ galactosidase-positive, myelin-forming cells were found within the caudoputamen when transgenic preparations were inserted directly into that region (Fig. 6).

\section{DISCUSSION}

The subventricular zone of the lateral ventricle is thickened at the ventricle's dorsolateral margin. This region is the site of intense mitosis during postnatal development, giving rise to oligodendrocyte precursors which, dividing further, populate the cerebral cortex and subcortical white matter and finally differentiate (e.g. /1,3/). In the present study, we removed small pieces from this area of the subventricular zone of transgenic mice and placed them in nearby cerebral cortex of wild type hosts. The tissue pieces contained no $\beta$ galactosidase-positive cells at the time of transplantation but did give rise to $\beta$-galactosidasepositive oligodendrocytes during subsequent development, indicating that the subventricular zone is an effective source of oligodendrocyte progenitors. The transplant-derived oligodendrocytes were dispersed in subcortical white matter and cerebral cortex near the grafts, indicating that oligodendrocytes or, more likely, their progenitors migrated from the grafted tissue plugs into surrounding host tissue.

In the developing oligodendrocytes of immature MßP3 transgenic mice, double immunofluorescence shows that transgene expression initiates after the expression of cyclic nucleotide phosphohydrolase and concomitant with the expression of the native MBP gene $/ 2 /$. The presence of the transgenic $\beta$-galactosidase in the transplant recipients thus indicates that the graftderived oligodendrocytes are differentiated to the point of expressing MBP. That many of these engrafted cells make myelin sheaths is strongly suggested by the characteristic histochemical staining pattern found around labeled somas, attributed to transplant-derived oligodendrocyte processes and myelin sheaths (Fig. 4B).

Transgenic oligodendrocytes were common in dorsal subcortical white matter but they did not appear in myelinated bundles of the caudoputamen. These bundles are in direct continuity with the subcortical white matter (Fig. 5) and, in fact, 
A

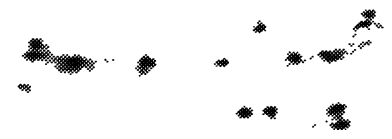

B.
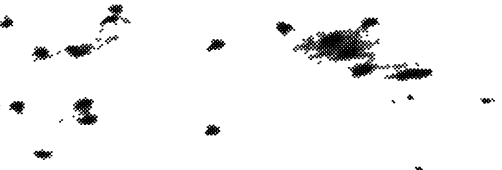

Fig. 4: Transplant-derived oligodendrocytes and myelin, visualized by $\mathrm{X}$-gal staining. A: distribution of $\mathrm{X}$ gal stain following engraftment into cerebral cortex is limited to cerebral cortex and subjacent white matter. B: Cell bodies are labeled, as are myelin sheaths derived from the labeled cells. Scale bars: 1 $\mathrm{mm}$ (A); $100 \mu \mathrm{m}$ (B).

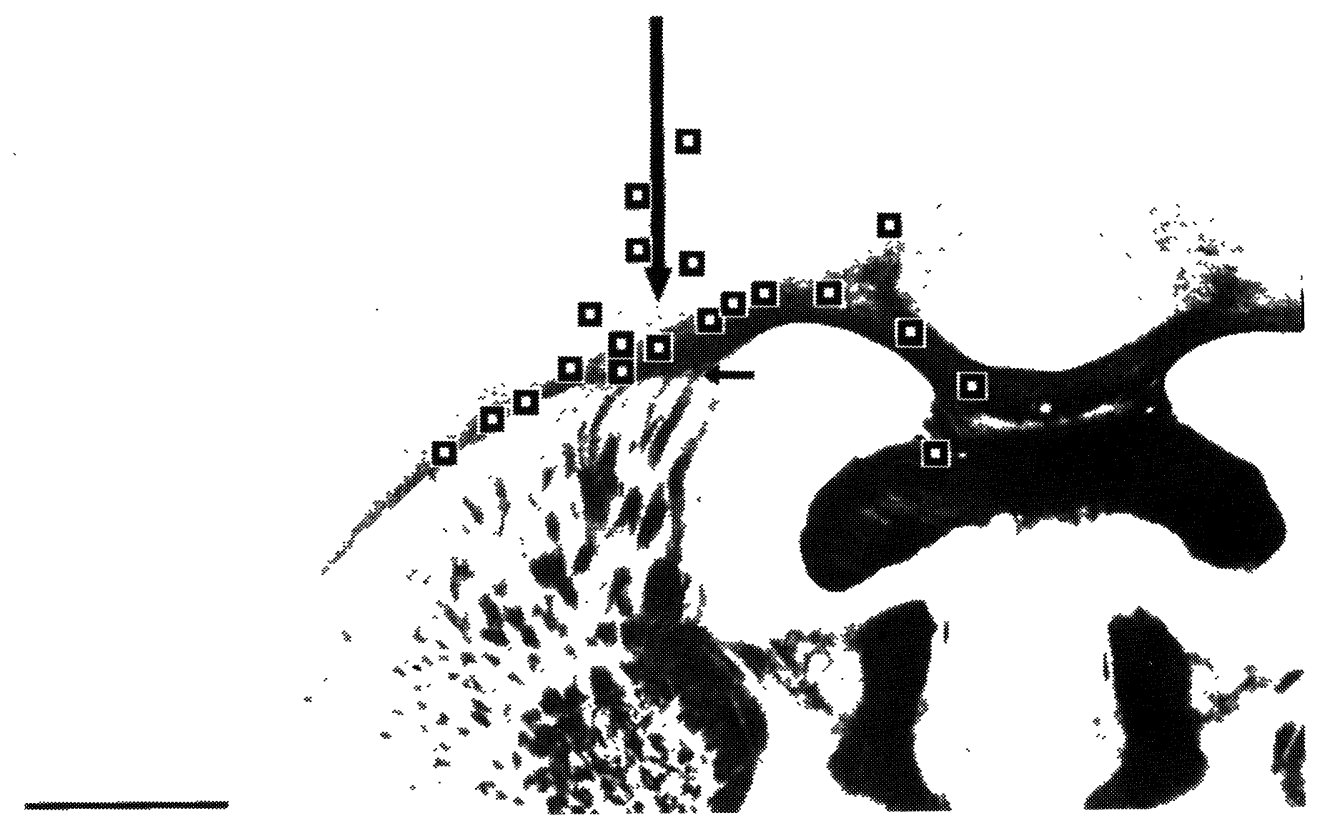

Fig. 5: Distribution of labeled oligodendrocytes after implantation in cerebral cortex near subcortical white matter; mouse brain viewed in coronal section. Labeled oligodendrocytes (boxes) are distributed in callosal radiations, subcortical white matter and cerebral cortex but not in nearby caudoputamen. The approximate site of implants is indicated by the large arrow. The small arrow indicates one of many points of continuity between subcortical white matter and myelinated axon bundles of the caudoputamen. The diagram is a schematic summarizing the results from eight animals. Scale bar, $1 \mathrm{~mm}$. 


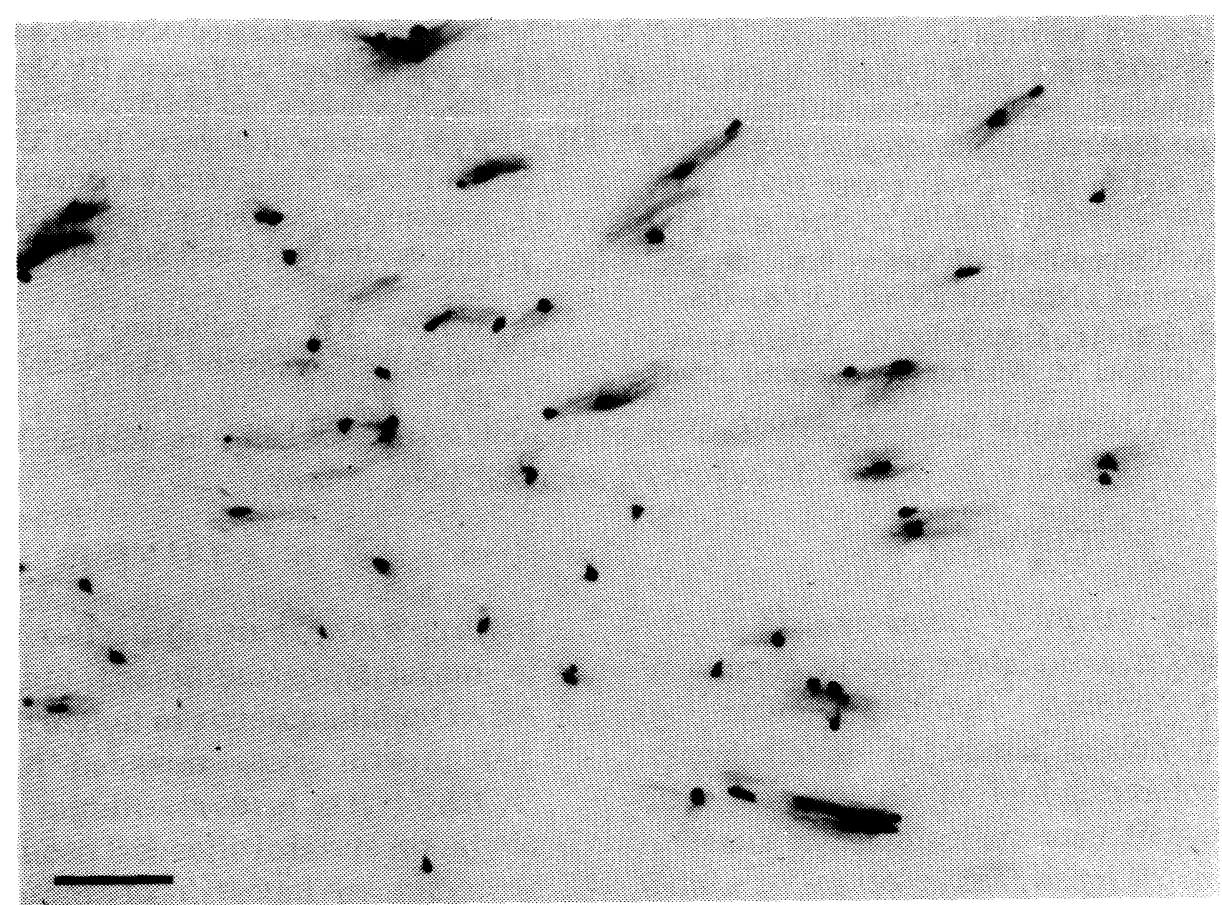

Fig. 6: Labeled oligodendrocytes are dispersed in the caudoputamen after deeper implant of transgenic cells, indicating that the caudoputamen is capable of supporting the differentiation of transplanted, transgenic oligodendrocytes when implanted in that structure.

contain axons which run to and from the subcortical white matter. Although no barrier to migration between the two regions is apparent, it appears that oligodendrocyte progenitors migrated along the subcortical white matter without entering the contiguous caudoputamen. This single example suggests that migration of transplanted oligodendrocyte progenitors, and quite possibly that of endogenous oligodendrocyte progenitors as well, is directed or restricted by mechanisms yet to be identified.

The strategy employed here uses a transgene so structured that its marker enzyme is expressed only in differentiated cells of a particular phenotype. This approach does not mark undifferentiated cells nor cells of other types; in transplantation experiments, the presence of the marker documents simultaneously the source and the state of differentiation of the marked cells. In this study, we found that the transplanted subventricular zone gives rise to differentiated oligodendrocytes which populate the host tissue surrounding the grafts. This approach may prove fruitful in further analysis of oligodendroglial migration and differentiation during development and of transplant contribution to repair from demyelination.

\section{ACKNOWLEDGEMENTS}

This is publication \#124 from the Brookdale Center for Molecular Biology of the Mount Sinai School of Medicine. These studies were supported by NIH grant NS29056 (R.L.) and grants RG-2238A-1 (R.L.) and PP0220 (V.F.) from the National Multiple Sclerosis Society. We thank Xue Li for his excellent technical contributions.

\section{REFERENCES}

1. Goldman JE, Vaysse PJ-J. Tracing glial cell lineages in the mammalian forebrain. Glia 1991; 4: 149-156.

2. Gow A, Friedrich VL Jr, Lazzarini RA. Myelin basic protein gene contains separate enhancers for 
oligodendrocyte and Scliwann cell expression. J Cell Biol 1992; 119: 605-616.

3. Hardy R, Reynolds R. Proliferation and differentiation potential of rat forebrain oligodendroglial progenitors both in vitro and in vivo. Development 1991; 111: 1061-1080.

4. Horrocks LA. Composition of mouse brain myelin during development. J Neurochem 1968; 15: 483-488.

5. Lachapelle F, Lapie P, Gansmuller A, Villarroya H, Baumann N, Gumpel M. What have we learned about the jimpy phenotype expression by intracerebral transplantations? In: Duncan ID, Skoff RP, Colman D, eds, Myelination and Dysmyelination. New York: New York Academy of Sciences, 1990; 332-345.

6. Rio-Hortega $P$ del. Tercera aportación al conocimiento morfológico e interpretación functional de la oligodendroglia. Mem R Soc Exp Hist Nat 1928; 14: 5122.

7. Sturrock RR. Myelination of the mouse corpus callosum. Neuropathol Appl Neurobiol 1980; 6: 415420. 

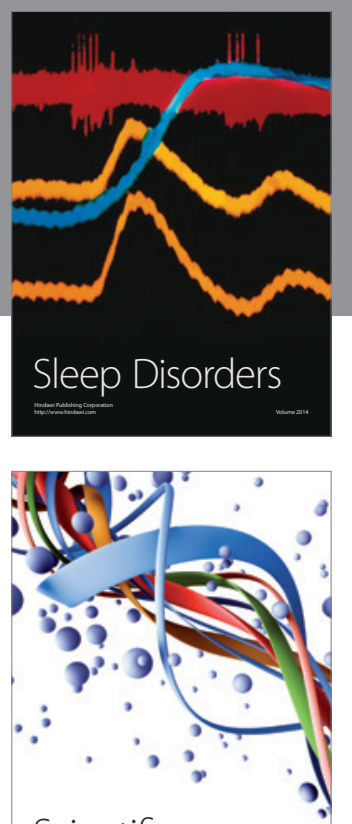

Scientifica
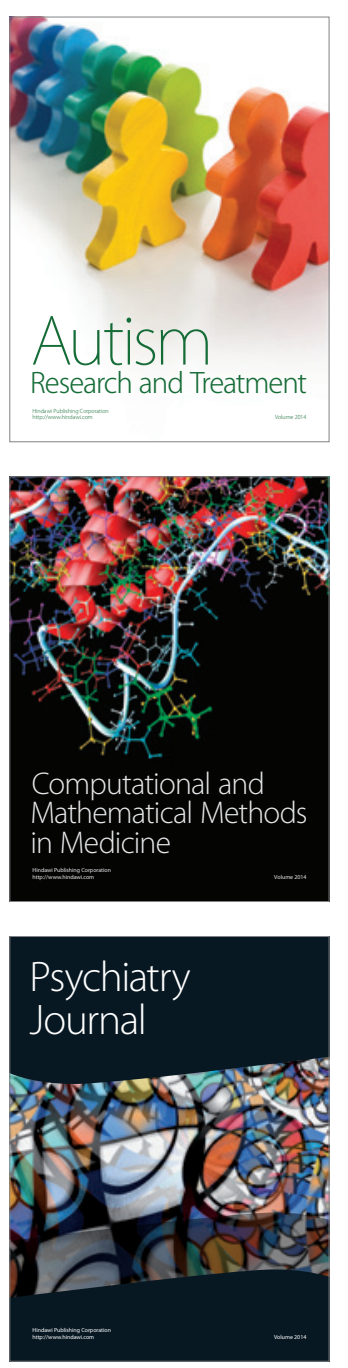
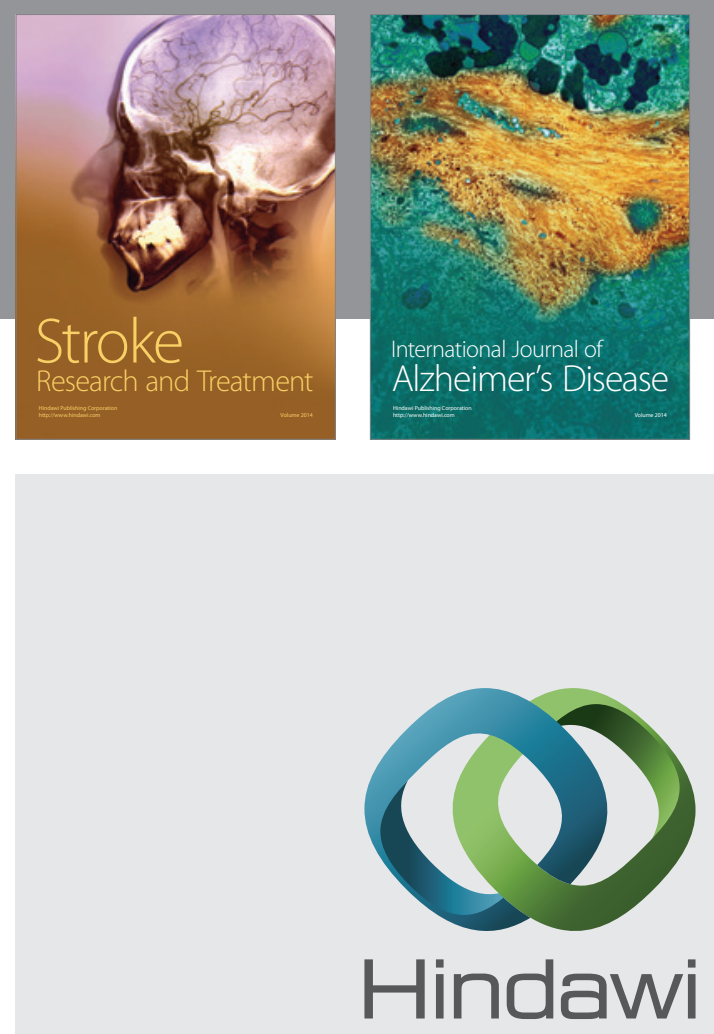

Submit your manuscripts at

http://www.hindawi.com
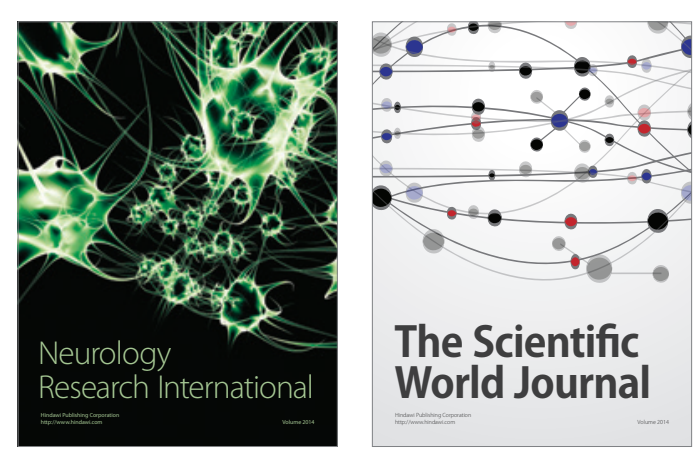

The Scientific World Journal

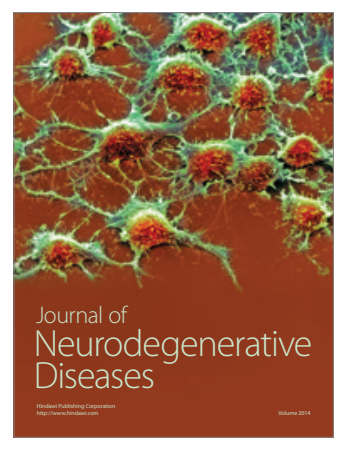

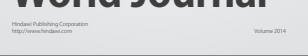

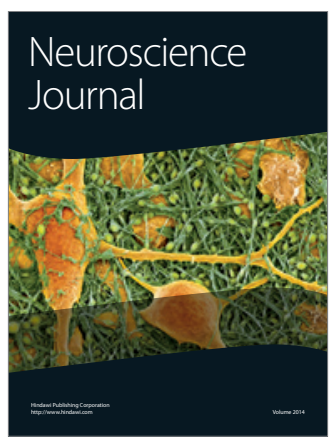

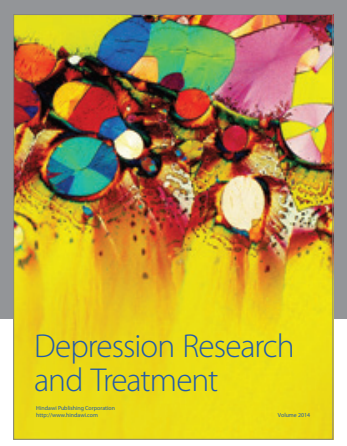
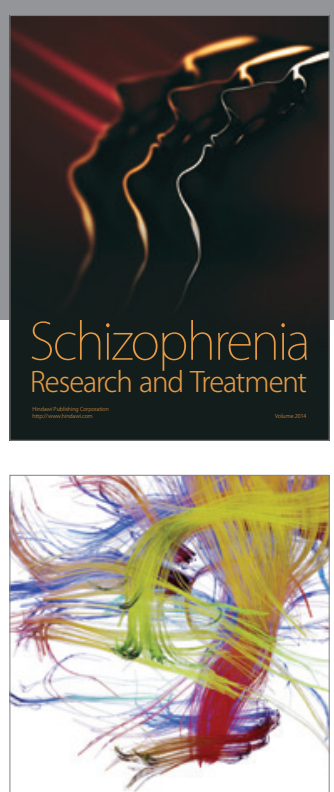

Brain Science

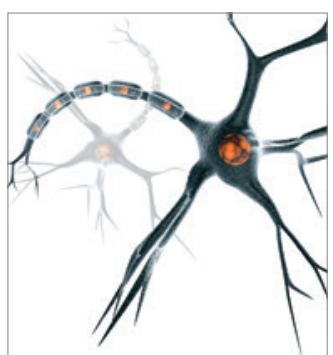

Neural Plasticity
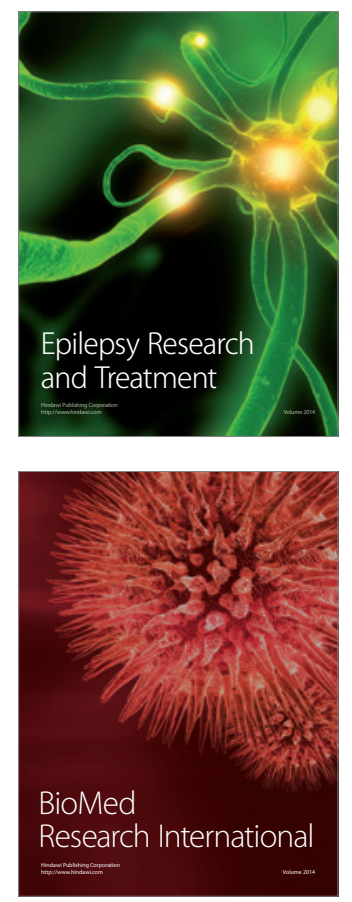

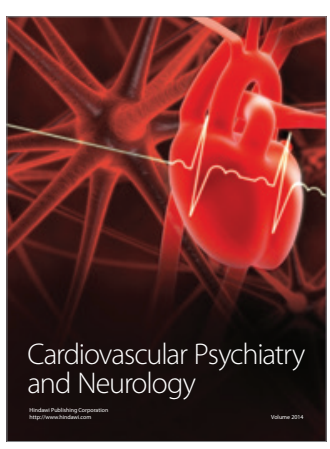

Parkinson's

Disease
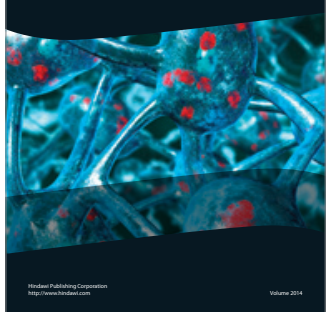